\title{
KESEIMBANGAN DASAR SUNGAI PADA BELOKAN SEDANG (II) DENGAN UJI MODEL FISIK KRIB PERMEABEL BAN MOBIL BEKAS
}

\author{
I Made Udiana ${ }^{1 *}$ \\ ${ }^{1}$ Teknik Sipil Universitas Nusa Cendana \\ Jalan Adi Sucipto, Penfui, Kupang, NTT \\ *E-mail: imadeudiana10@gmail.com
}

\begin{abstract}
Abstrak
This research is aimed at analyzing the slope is average in a model of river bed, the slope of each section and the maximum depth of the degradation which result from the construction of permeable on the model for the river that is using moderate bends (II), of minimum discharge, average discharge and maximum discharge, in order to determine the proper course of water flow, so as to achieve balance in river beds. The scour area of the permeable groyne formation is perpendicular to the scour I (ATLG I) $=0,4800 \mathrm{~m} 2$ with benchmarks ATLG I $<$ SeDKP and scour II (ATLG II) = 0,6000 m with benhmarks ATLG II < SeDKP and the average slope of the river bed that occurs and the average slope of the river bed that occurs (Ids TL) $=0,0097$ with benchmarks IdsTL < SeDKP so that the balance of the river bed is achieved and the hypothesis is accepted.
\end{abstract}

Keywords: The balance, Moderate bends, Physical model test, Permeable groyne, Second hand car tire

\section{PENDAHULUAN}

Perubahan dasar sungai akan berlangsung terus menerus, sehingga dapat mempengaruhi morfologi sungai dan perlahanlahan berpengaruh pada kestabilan sistem. Usaha sungai untuk mencapai kestabilan itu, menyebabkan timbulnya belokan pada sungai. Pengaturan keseimbangan dasar pada belokan sungai yaitu untuk mengatasi adanya penggerusan pada sisi belokan luar dan pengendapan pada sisi belokan dalam. Usaha pengaturan sungai (river training) dengan memasang susunan krib jenis tertentu sedemikian rupa ditujukan untuk mengatur dan mengurangi penggerusan dan pengendapan. Penempatan bangunan pengatur pada belokan sungai seperti krib permeabel diharapkan akan dapat menstabilkan dasar sungai. Pemasangan krib permeable diharapkan akan mendistribusikan kecepatan untuk menjadi lebih seragam dan mengatur arah aliran dengan baik, sehingga tercapai keseimbangan dasar sungai.

Dengan melihat jenis-jenis material yang sudah ada untuk konstruksi krib permeable seperti kayu, beton, bronjong kawat dan baja, maka timbul gagasan penulis menggunakan ban mobil bekas sebagai alternatif untuk konstruksi tersebut. Jenis ban mobil bekas yang dipakai untuk konstruksi krib permeabel adalah jenis ban radial (bekas) dari ban mobil ukuran 195/60 HR 15, karena tersedianya ban jenis ini di lapangan cukup banyak, mudah didapat dan harganya cukup murah. Penggunaan ban mobil bekas mempunyai kekuatan yang baik, awet, sangat fleksibel, aman dari faktor hidrologi, hidraulik dan konstruksi serta merupakan rekayasa teknik sebagai teknologi ramah lingkungan serta dapat memberikan pengetahuan baru selain jenis-jenis material yang sudah ada untuk konstruksi krib permeabel. Penggunaan ban mobil bekas untuk krib permeabel belum ada serta kefektifannya perlu diuji

Sehubungan dengan penggunaan ban mobil bekas untuk konstruksi krib permeabel, maka rencana teknis dari krib permeabel adalah konstruksi bercelah (lulus air) menggunakan ban mobil bekas tipe 195/60 HR 15. Konstruksinya direncanakan terdiri dari susunan ban posisi berdiri/tegak dengan matras beton terdiri dari tiga baris ban yang masing-masing baris terdiri dari lima ban di susun dua susun ke atas dan pada setiap satu susun ban diikatkan pada bantalan beton

\section{METODE PENELITIAN}

\section{Lokasi Penelitian}

Tempat penelitian pengujian model fisik konstruksi krib permeable menggunakan ban mobil bekas 195/60 HR 15 pada belokan sedang (II) terhadap keseimbangan dasar sungai pada model sungai di Laboratorium 
Teknik Sungai dan Rawa, Jurusan Teknik Pengairan, Fakultas Teknik, Universitas Brawijaya.

\section{Bahan dan Alat Penelitian Bahan penelitian}

Bahan untuk penelitian tentang pengujian model fisik konstruksi krib permeabel menggunakan ban mobil bekas pada belokan sungai terhadap keseimbangan dasar sungai untuk model sungai dasar tidak tetap (movable bed models) dengan skala distorsi di Laboratorium Sungai dan Rawa, Jurusan Teknik Pengairan, Fakultas Teknik, Universitas Brawijaya yaitu : air, tanah, pasir, semen, kerikil, batubara, kawat beton, triplex $5 \mathrm{~mm}$, benang, paku, usuk, reng dan slang phonix presser luft DIN 20018-2001 (karet) diameter $30 \mathrm{~mm}$.

\section{Alat penelitian}

Penelitian ini dilakukan dengan menggunakan peralatan yang ada di Laboratorium Sungai dan Rawa, Jurusan Teknik Pengairan, Fakultas Teknik, Universitas Brawijaya. Karakteristik peralatan yang digunakan yaitu bak penampung air, pompa air (diesel), model fisik sungai dengan belokan, alat ukur debit jenis Rechbox, alat ukur kecepatan aliran (current meter), theodolit dan perlengkapannya, alat duga muka air (meteran taraf), penyipat datar (water pass), jam yang jarumnya dapat dijalankan dan dihentikan untuk mengukur waktu (stop watch), jaringjaring, busur derajat, gunting, tang, palu, bak penenang hulu dan bak penampung sedimen hilir.

\section{Perencanaan model fisik konstruksi krib permeabel}

Model fisik konstruksi krib permeabel adalah bercelah (lulus air) menggunakan ban mobil bekas ukuran 195/60 HR 15. Konstruksinya direncanakan terdiri dari susunan ban posisi berdiri/tegak dengan matras beton terdiri dari tiga baris ban yang masing-masing baris terdiri dari lima ban di susun dua susun ke atas dan pada setiap satu susun ban diikatkan pada bantalan beton. kemudian di antara masing-masing susunan ban diisi beton isian campuran $1 \mathrm{PC}: 3$ pasir : 5 kerikil. Krib permeabel ini panjangnya sebesar 1/5 dari lebar model sungai, lebarnya sama dengan satu kali diameter ban, tinggi krib lebih kurang 3/5 dari kedalaman air maksimum dan jarak antara krib diambil dua kali panjang krib. Formasi pemasangan krib permeabel pada model sungai dengan belokan sedang (II) adalah condong ke hulu, tegak lurus dan condong ke hilir dengan sudut condong krib ( $\square$ ) sebesar $15^{\circ}$

\section{HASIL DAN PEMBAHASAN}

Data Prototipe Pada Belokan

\begin{tabular}{llll}
\hline Penampang & $:$ trapesium & Vp min & $: 1,1047 \mathrm{~m} / \mathrm{dt}$ \\
\hline Talud & $: 1: 2$ & Vp rata2 & $: 1,3696 \mathrm{~m} / \mathrm{dt}$ \\
\hline Lebar (B) & $: 30 \mathrm{~m}$ & Vp max & $: 1,5647 \mathrm{~m} / \mathrm{dt}$ \\
\hline $\mathrm{n}$ & $: 0,025$ & Cp min & $: 39,962$ \\
& & & $\mathrm{~m}^{1 / 2} / \mathrm{dt}$ \\
\hline$\rho \mathrm{s}$ & $: 2990 \mathrm{~kg} / \mathrm{m3}$ & Cp rata2 & $: 41,580$ \\
& & & $\mathrm{~m}^{1 / 2} / \mathrm{dt}$ \\
\hline $\mathrm{m}$ & $: 0,50$ & Cp max & $: 42,503$ \\
& & & $\mathrm{~m}^{1 / 2} / \mathrm{dt}$ \\
\hline Ip & $: 0,000575$ & C90pmin & $: 60,721$ \\
& & & $\mathrm{~m}^{1 / 2} / \mathrm{dt}$ \\
\hline D50p & $: 0,00275 \mathrm{~m}$ & C90prata & $: 63,462$ \\
& & & $\mathrm{~m}^{1 / 2} / \mathrm{dt}$ \\
\hline D90p & $: 0,00675 \mathrm{~m}$ & C90max & $: 65,200$ \\
& & & $\mathrm{~m}^{1 / 2} / \mathrm{dt}$
\end{tabular}

Spesifikasi Teknik Ban Mobil Bekas di Prototip dan di Model

\begin{tabular}{|c|c|c|c|c|}
\hline $\begin{array}{l}\text { Spesifikasi } \\
\text { Teknik } \\
\text { Ban Mobil } \\
\text { Bekas }\end{array}$ & di $P$ & ototip & di N & odel \\
\hline $\begin{array}{l}\varnothing \text { luar ban } \\
\text { mobil } \\
\text { bekas }\end{array}$ & (Db) & $\begin{array}{l}: \\
60,00 \\
m\end{array}$ & $(\mathrm{Db})$ & $\begin{array}{l}: \\
3,00 \\
\mathrm{~cm}\end{array}$ \\
\hline $\begin{array}{l}\varnothing \text { dalam } \\
\text { ban mobil } \\
\text { bekas }\end{array}$ & $(\mathrm{Dd})$ & $\begin{array}{l}: \\
38,10 \\
m\end{array}$ & $(\mathrm{Dd})$ & $\begin{array}{l}: \\
2,00 \\
\mathrm{~cm}\end{array}$ \\
\hline $\begin{array}{l}\text { Tebal ban } \\
\text { mobil } \\
\text { bekas }\end{array}$ & $\begin{array}{l}\text { ( tb } \\
\text { ) }\end{array}$ & $\begin{array}{l}: \\
20,00 \\
m\end{array}$ & $\begin{array}{l}\text { ( tb } \\
\text { ) }\end{array}$ & $\begin{array}{l}: \\
1,00 \\
\mathrm{~cm}\end{array}$ \\
\hline
\end{tabular}


Kebenaran Model Sungai

\begin{tabular}{ccccc}
\hline Material & $\begin{array}{c}\text { D50 } \\
(\mathrm{mm})\end{array}$ & $\begin{array}{c}\text { D90 } \\
(\mathrm{mm})\end{array}$ & $\begin{array}{c}\rho \mathrm{s} \\
\left(\mathrm{kg} / \mathrm{m}^{3}\right)\end{array}$ & $\begin{array}{c}\mathrm{C} \\
\left(\mathrm{m}^{1 / 2} / \mathrm{dt}\right)\end{array}$ \\
\hline A & 0,500 & 1,597 & 2630 & 51,339 \\
B & 0,650 & 1,690 & 2647 & 50,898 \\
\hline
\end{tabular}

\section{Evaluasi Karakteristik Material}

Berdasarkan evaluasi karakteristik antara material A dan B, maka material B merupakan pilihan terbaik untuk belokan sedang (II) :

\begin{tabular}{clc}
\hline Belokan & Parameter & Material B \\
\hline & Kondisi Froude & 0,567 \\
& Kondisi Kekasaran & 0,334 \\
$\begin{array}{c}\text { Sedang } \\
\text { (II) }\end{array}$ & Tilting & $4,20 \times 10^{-5}$ \\
& Waktu morfologi & 83,616 \\
& Kesalahan max & 1,367 \\
& m.a & \\
\hline
\end{tabular}

Dengan menggunakan material $B$ kesesuaian model dapat tercapai dengan dukungan bukti sebagai berikut:

Kesebangunan Froude dan kesalahan muka air

Keadaan Model Sungai Sebelum Pengaliran pada Belokan Sedang (II)

\begin{tabular}{ccccc}
\hline Belokan & $\mathrm{B}(\mathrm{m})$ & $\mathrm{R}(\mathrm{m})$ & $\theta\left(^{\circ}\right)$ & $\begin{array}{c}\mathrm{Lm} \\
(\mathrm{m})\end{array}$ \\
\hline $\begin{array}{c}\text { Sedang } \\
\text { (II) }\end{array}$ & 0,75 & $2=7,5 \mathrm{~B}$ & $\begin{array}{c}2 \\
=100^{\circ}\end{array}$ & 22,66 \\
& 0,75 & $5=5,0 \mathrm{~B}$ & $5=50^{\circ}$ & \\
\hline
\end{tabular}

Kemiringan di model $=\operatorname{lm}=1,15 \times 10^{-3}$

Analisa dan Pembahasan Kondisi Model Sebelum Dipasang Krib Permeabel
Jenis aliran dengan bilangan Froude $\mathrm{Fr}<1,0$ berarti sub kritis, sifat aliran dengan bilangan Reynold $\operatorname{Re}>12500$ berarti turbulen, kondisi butiran Um > Ucr berarti bergerak, kondisi hidraulik dominan hidraulik kasar, klasifikasi regime aliran $\mathrm{Fr}<0,4-1,0$ berarti regime aliran rendah dan bentuk dasar berdasarkan $\mathrm{Fr}$ dan $\mathrm{U} / \mathrm{U}^{*}$ dunes. Akibat perlakuan model pada belokan sedang (II) sesudah pengaliran sebelum dipasang bangunan krib permeable dengan kondisi debit maksimum, maka didapat panjang gerusan pertama sebesar 2,10 $\mathrm{m}$ dan gerusan kedua sebesar 2,33 m (5.6/78)

Kemiringan rata-rata yang terjadi (Irt) pada model sungai dengan belokan sedang (II) dari awal sampai akhir belokan yaitu section 1-9 $(5.6 / 80)$ sebagai berikut :

\begin{tabular}{cccc}
\hline $\begin{array}{c}\text { Model } \\
\text { sungai }\end{array}$ & \multicolumn{2}{c}{ Kemiringan rata-rata (Irt) kondisi } \\
& Qmin & Qrata-rata $(\mathrm{Q})$ & Qmax \\
& & & \\
\hline $\begin{array}{c}\text { Belokan } \\
\text { sedang } \\
\text { (II) }\end{array}$ & 0,00112 & 0,00124 & 0,00125 \\
& & & \\
\hline
\end{tabular}

\section{Analisa dan Pembahasan Kondisi Model Sesudah Dipasang Krib Permeabel}

Jenis aliran dengan bilangan Froude $\mathrm{Fr}<1,0$ berarti sub kritis, sifat aliran dengan bilangan Reynold $\operatorname{Re}>12500$ berarti turbulen, kondisi butiran Um > Ucr berarti bergerak, kondisi hidraulik dominan hidraulik kasar, klasifikasi regime aliran $\mathrm{Fr}<0,4-1,0$ berarti regime aliran rendah dan bentuk dasar berdasarkan $\mathrm{Fr}$ dan $\mathrm{U} / \mathrm{U}^{*}$ dunes.

Kemiringan rata-rata (Irt) yang terjadi sesudah dipasang krib permeabel di model sungai belokan sedang (II) pada formasi pemasangan krib permeabel condong ke hulu (IIA), tegak lurus (IIB) dan condong ke hilir (IIC) dengan kondisi debit maksimum sebesar 0,00097.

Berdasarkan hasil percobaan sesudah 
pengaliran terhadap jumlah kebutuhan dan perlakuan sebelum dan sesudah pemasangan krib permeabel pada belokan sedang (II) di model sungai untuk kondisi maksimum (5.9/97) adalah sebagai berikut:

\begin{tabular}{|c|c|c|c|}
\hline \multirow[t]{2}{*}{ Kondisi } & \multirow[t]{2}{*}{$\begin{array}{c}\text { Pemasang } \\
\text { an Krib } \\
\text { permeabel }\end{array}$} & \multicolumn{2}{|c|}{$\begin{array}{c}\text { Belokan sedang } \\
\text { dan Krib } \\
\text { permeabel } \\
\text { condong ke hulu } \\
\text { (IIA), tegak lurus } \\
\text { (IIB) condong ke } \\
\text { hilir (IIC) }\end{array}$} \\
\hline & & $\begin{array}{c}\text { Gerusa } \\
\text { n I }\end{array}$ & $\begin{array}{c}\text { Gerusa } \\
\text { n II }\end{array}$ \\
\hline \multirow{2}{*}{$\begin{array}{l}\text { Kedalam } \\
\text { an } \\
\text { gerusan } \\
\max (Z)\end{array}$} & $\begin{array}{l}\text { Sebelum } \\
(\mathrm{m})\end{array}$ & 0,0825 & 0,0875 \\
\hline & $\begin{array}{l}\text { Sesudah } \\
(\mathrm{m})\end{array}$ & 0,0765 & 0,0800 \\
\hline \multirow{2}{*}{$\begin{array}{l}\text { Luas } \\
\text { gerusan } \\
\text { (A) }\end{array}$} & $\begin{array}{l}\text { Sebelum } \\
\text { (m2) }\end{array}$ & 0,0765 & 1,4400 \\
\hline & $\begin{array}{l}\text { Sesudah } \\
\text { (m2) }\end{array}$ & 0,4800 & 0,6000 \\
\hline $\begin{array}{l}\text { Kecepata } \\
\mathrm{n} \text { rata2 } \\
(\mathrm{Vr})\end{array}$ & $\begin{array}{l}\text { Sesudah } \\
\text { (m/dtk) }\end{array}$ & \multicolumn{2}{|c|}{0,4427} \\
\hline
\end{tabular}

Berdasarkan kedalaman gerusan maksimum, luas gerusan dan kecepatan rata-rata yang terjadi di model dan di prototip pada kondisi debit maksimum, maka formasi pemasangan pemasangan krib permeabel alternatif terbaik pada model sungai dengan belokan sedang (II) adalah formasi tegak lurus (TL).

\section{PENUTUP}

1. Akibat perlakuan model pada belokan sedang (II) sesudah pengaliran sebelum dipasang bangunan krib permeable dengan kondisi debit maksimum, maka didapat panjang gerusan pertama sebesar $2,10 \mathrm{~m}$ dan gerusan kedua sebesar 2,33 $\mathrm{m}$. Kemiringan rata-rata yang terjadi (Irt) pada model sungai dengan belokan sedang (II) dari awal sampai akhir belokan yaitu section 1- 9 pada kondisi debit minimum (Qmin) sebesar 0,00112, kondisi debit rata-rata (Qrata-rata) sebesar 0,00124 dan kondisi debit maksimum (Qmax) sebesar 0,001250.

2. Pemasangan krib dengan alternatif terbaik terjadi pada belokan sedang (II) dengan perlakuan sesudah dipasang krib permeabel dengan formasi tegak lurus karena mendapatkan:

a. Kedalaman gerusan maksimum gerusan I sebesar 0,0765 dan pada gerusan II sebesar 0,0800 ,

b. Luas gerusan I sebesar 0,4800 dan gerusan II sebesar 0,6000 .

c. Kemiringan rata-rata dasar sungai yang terjadi pada formasi krib tegak lurus sebesar 0,0097.

3. Pemasangan krib permeabel efektif karena dapat mengarahkan aliran ke tengah sungai, sehingga dapat memberikan keseimbangan dasar sungai.

4. Keuntungan yang didapat dengan menggunakan ban mobil bekas ukuran 195/60 HR 15 untuk konstruksi krib permeabel adalah sebagai berikut :

a. Penggunaan ban mobil bekas efektif karena dapat mengatasi kelemahan dari material yang sudah ada untuk konstruksi kribpermeabel, yaitu bisa digunakan pada sungai aluvial dan berkerikil dan satu jenis material ban mobil bekas dapat digunakan untuk dua konstruksi.

b. Kekuatannya baik, awet, fleksibel dan aman terhadap faktor hidrologi, faktor konstruksi dan faktor hidraulik.

c. Ketersediaannya di pasaran cukup banyak dan harganya murah.

\section{DAFTAR PUSTAKA}

Anonim. 1981. Tikungan Sungai dengan Keadaan Hidrolisnya, Sedimen Transport, Penggerusan dan Pengendapan dan Kestabilan Tikungan, Departemen Pekerjaan Umum-Direktorat Penyelidikan Masalah Air.

Anonim. 1989. Debris Flow, Departemen Pekerjaan Umum-Direktorat Penyelidikan Masalah Air, Yogyakarta.

Anonim. 1997. Torrent Hidraulic, Departemen Pekerjaan Umum-Direktorat Penyelidikan Masalah Air, Yogyakarta.

Balachandar, R. and Kells, J. A. 1997. Local Channel Scour in Uniformly Graded Sediments : The TimeScale Problem, Canadian Journal of Civil Engineering, $24: 799-807$.

Chaudhry, M. Hanif. 1993. Open-Channel Flow, Prentice Hall, Englewood Cliffs, New Jersey.

De Vries, M. 1977. Scale Models in Hydraulic Engineering, Delft University of Technology, Delft.

Fauzan B.M. 2001. Memilih dan Merawat Ban Mobil, Puspa Swara, Jakarta. 
Hoffmans, G. J. C. M. and Pilarczyk, K. W. 1995. Local Scour Downstream of Hydraulic Structures, Journal of Hydraulic Engineering, 121 (4) : 326340.

Hsieh, Wen Shen. 1979. Modeling of River, John Wiley \& Son, Canada

Reinauer, R. and Hager, W. H. 1997. Supercritical Bend Flow, Journal of Hydraulic Engineering, 123 (3) : 208-218.

Sasongko, D. 1995. Teknik Sumber Daya Air, Edisi Ketiga, Terjemahan, Ray K. Linsley, Joseph B. Franzini, Erlangga, Jakarta.

Subramanya, K. 1984. Flow In Open Channels, First Revised Edition, Tata McGraw-Hill Publishing Company Ltd., New Delhi.

Walter Hans. 1984. Hydraulic of Sediment Transport, Water Resources Publication, Michigan-USA.

Wilson, E. M. 1993. Hidrologi Teknik, Penerbit Institut Teknologi Bandung, Bandung Jansen, P.Ph. et al. 1979. Principle of River Engineering, Pitman Publication, London.

Kinori, B.Z. and Mevorach, J. 1984. Manual of Surface Drainage Engineering, Volume II, Elsevier, London.

Legono, D.1987. Morfologi Sungai, PAU-UGM, Yogyakarta.

Novak, P. and Cabelka, J. 1981. Models in Hydraulics Engineering, Delft University of Technologi, Delft.

Nugroho, J. dkk. 2001. Optimasi Pemasangan Krib di Saluran Menikung, PIT XVIII, HATHI, Malang. Hal. 56-65.

Patersen, Margaret, S. 1986. River Engineering, Prentice Hall, New Jersey.

Pilarczyk, K.W. et al. 1995. River Training Techniques, AA Balkema, Rotterdam.

Priyantoro, Dwi. 1987. Teknik Pengangkutan Sedimen, Himpunan Mahasiswa Pengairan Fakultas Teknik-Universitas Brawijaya, Malang. 